\title{
Imigração, língua de acolhimento e assimilação em Goiás
}

\author{
Immigration, target language and assimilation in Goiás
}

Inmigración, lengua de acogida y asimilación en Goiás

\author{
(iD) Juan Alberto Castro Chacón \\ Universidade Federal de Goiás (UFG), Goiânia, Goiás, Brasil. \\ e-mail: infonauta2@gmail.com
}

Resumo: Esta pesquisa reflete sobre língua de acolhimento ao imigrante, na língua portuguesa em Goiás - Brasil, fazendo um trajeto historiográfico pela formação da sociedade goiana, no séc. XX (PALACíN; MORAES, 2008). O estudo destaca a assimilação sociolinguística com que as etnias foram acolhidas pelo português, por necessidade ou afetividade (CAMBRIDGE, 2000). Nesse ponto, os estudos de Braggio (1992) direcionam a aquisição da língua à realidade sociocultural; consequentemente, fazemos descrições referenciais sobre a imigração em Goiás. Assim, nossa pesquisa discutiu sobre a identidade (SILVA, 2007), na organização da língua de acolhimento (AMADO, 2013), na aquisição de língua e a assimilação linguística do imigrante.

Palavras-chave: Imigração. Língua de acolhimento. Assimilação linguística. Goiás.

\begin{abstract}
This research reflects on the target language to the immigrants, in the Portuguese language in Goiás - Brasil, making a historiographic path through the formation of goiana society in the twentieth century (PALACÍN; MORAES, 2008). The study highlights the socio-linguistic assimilation with which different ethnic groups welcomed Portuguese due to need or affectivity (CAMBRIDGE, 2000). Regarding this point, Braggio's (1992) studies direct the acquisition of language to the sociocultural reality; consequently, we make referential descriptions about
\end{abstract}


immigration in Goiás. Thus, our research discussed identity (SILVA, 2007) in the organization of the target language (AMADO, 2013), as well as in the language acquisition and the linguistic assimilation of the immigrant.

Keyworks: Immigration. Target language. Linguistic assimilation. Goiás.

Resumen: Esta investigación reflexiona sobre lengua de acogida al imigrante, en la lengua portuguesa en Goiás - Brasil, recorriendo historiográficamente por la formación de la sociedad goyana, en el s. XX (PALACÍN; MORAES, 2008). El estudio destaca la asimilación sociolingüística con que acogieron el portugués varias etnias, por necesidad o afectividad (CAMBRIDGE, 2000). En este punto, los estudios de Braggio (1992) dirigen la adquisición de lengua a la realidad sociocultural; consecuentemente, describimos referencias sobre la inmigração en Goiás. Así, nuestra investigación discutió sobre la identidad (SILVA, 2007), en la organización de la lengua de acogida (AMADO, 2013), dentro de la adquisición de lengua y la asimilación lingüística del inmigrante.

Palabras-clave: Inmigración. Lengua de acogida. Asimilación lingüística. Goiás.

Submetido em 28 de fevereiro de 2021.

Aceito em 22 de abril de 2021.

Publicado em 03 de novembro de 2021. 


\section{Considerações Iniciais}

Para a realização desta pesquisa devemos levar em conta que a aquisição de uma língua se dá com diversas estratégias e em múltiplos aspectos socioculturais, como bem mencionam os estudos da professora Sílvia Braggio em Leitura e alfabetização (1992).

Neste trabalho, a manifestação e a representação da língua equivalem à trajetória de uma cultura, na tentativa de fazer uma relação indissociável entre ambas as manifestações humanas. Por conseguinte, descrever a prática da língua portuguesa no mundo é uma tarefa difícil, porém, detalhar a sua prática no Brasil torna-se um desafio, enquanto língua de difusão em condições multiculturais. Nesse sentido, a nossa investigação aponta para um escopo mais específico, como é o português utilizado na região Centro-Oeste do Brasil, mais detalhadamente no Estado de Goiás.

Dessa maneira, colocamos os grupos imigrantes no Estado de Goiás frente à aquisição da língua portuguesa neste contexto espacial. Refletimos ainda sobre os níveis de assimilação linguística sofridos pelos estrangeiros e a sua construção/reformulação de identidade.

Nessa perspectiva, colocamos o imigrante como possuidor de um sistema linguístico já estabelecido, mas com novos desafios linguísticos, no que tange à necessidade de aprender e apreender a cultura na qual se insere. Ou seja, o imigrante é um ser já alfabetizado, com uma língua materna estabelecida e com um processo de inferências que vão além da comparação étnico-cultural.

Assim, os estudos de Rosane de Sá Amado (2013) mostram que o imigrante precisa se integrar no contexto sociocultural que o acolhe, priorizando o novo sistema linguístico, em primeiro lugar, para subsidiar suas necessidades básicas. Em segundo lugar, a língua de acolhimento torna-se ferramenta de ajuda para que o imigrante possa desenvolver sua leitura sociocultural, pensando que ele não está apenas "de passagem" por essa nova terra e pre- 
tende se estabelecer. Outro fator é que o imigrante não terá mais que se alfabetizar no sentido estrito da palavra, mas aprender a ler o novo espaço cultural, decodificar suas experiências e confrontá-las, já que se coloca na posição do "outro" olhado pelo "nós cultural" estabelecido.

Consequentemente, no contexto sociocultural goiano, a chegada de imigrantes de diversas partes do mundo foi um dos pilares para a fundação e a urbanização da nova capital de Goiás, a cidade de Goiânia, na primeira metade do séc. XX. Estes grupos migratórios participaram ativamente da grande empreitada de criação do movimento econômico e urbanístico da cidade goianiense, iniciada por grupos vindos de outros cantos do Brasil e, após (ou paralelamente), por sírio-libaneses, italianos, japoneses e sul-americanos. É, justamente, nesses estrangeiros, em que focamos as nossas reflexões.

Dessa forma, com um referencial historiográfico-bibliográfico, a nossa pesquisa reflete sobre a língua portuguesa no Brasil, utilizada em Goiás, para pensarmos como os imigrantes citados acima conseguiram organizar e adotar esse novo contexto sociocultural. Acreditamos que, embora tenha havido um primeiro momento de etnocentrismo, a língua portuguesa serviu como ferramenta de acolhimento e que a grande maioria de imigrantes conseguiu assimilá-la linguisticamente.

Por essa perspectiva, nossa pesquisa está dividida em três partes: primeiro, fazemos as discussões teóricas sobre a língua de acolhimento e alfabetização, além de esclarecer o campo semântico do termo leitura, em razão de um olhar para além da instrumentalidade. Na segunda parte, iniciamos com a discussão do contexto imigração e as problemáticas envolvidas nesse processo, trabalhando com temas como cultura, identidade e etnocentrismo. Posteriormente, fazemos um levantamento de dados historiográficos e bibliográficos sobre as imigrações em Goiás, nos grupos étnicos mencionados, visando reconhecer, nas suas trajetórias, o seu olhar sobre a língua e a cultura que os acolheu. Já na terceira parte, sugerimos reflexões sobre como o estado de Goiás repre- 
Imigração, língua de acolhimento e assimilação em Goiás

Juan Alberto Castro Chacon

sentou para o imigrante uma proposta de vida e uma aposta futura, no seu processo de assimilado, embora não haja parâmetros que possam delimitar a visão cultural do estrangeiro na sua plenitude.

\section{Alfabetização e língua de acolhimento.}

Nesta primeira parte, fazemos colocações sobre os estudos da professora e pesquisadora Sílvia Bigonjal Braggio, na obra Leitura e Alfabetização (1992), para relembrar algumas reflexões que a pesquisadora fez sobre esses dois conceitos que trabalham com a aquisição de língua.

Na mencionada obra, Braggio aponta a trajetória da concepção de linguagem/língua desde suas bases empiristas-behavioristas, passando pelas propostas estruturalistas e gerativistas, até o modelo sociopsicolinguístico, sem que, contudo, o processo de aquisição da linguagem esteja finalizado. É nesse sentido que, ao refletir sobre os modelos de aquisição da linguagem pelas crianças, Braggio (1992) afirma que:

Ao incentivar as crianças a "escreverem como sabem" no início do processo de aquisição, elas desenvolvem os princípios linguísticos, ou seja, elas internalizam a forma de organização da linguagem escrita em relação ao seu significado na cultura: os aspectos grafofônicos, sintáticos, semânticos e pragmáticos (p. 81).

Nesse comentário, a professora propõe ao significado de cultura, que as crianças fazem do seu processo de alfabetização, o fundamento para o desenvolvimento deste processo, isto é, a cultura como perspectiva/visão sobre o fator linguístico a aprender e, nesse sentido, compreender essas relações. Assim, podemos nos perguntar o que se entende por alfabetização e as suas sugestões na epistemologia da linguagem, sobretudo na realidade pedagógica. 
É, dessa questão, que Tfouni, na sua discussão sobre letramento e alfabetização (1995), menciona que:

\begin{abstract}
A alfabetização é definida, principalmente, em termos mecânicos e funcionais. Por um lado, é reduzida ao domínio de 'habilidades' (sic) fundamentais. Neste caso, é apresentada para como determinadas habilidades para usar a linguagem escrita [...] Desse modo, o ato de alfabetizar passa a existir somente enquanto parte das práticas escolares, e ignoram-se sistematicamente as práticas sociais mais amplas para as quais a leitura e escritura são necessárias, e nas quais serão efetivamente colocadas em uso (p. 17-18).
\end{abstract}

Nesse viés, vemos que a alfabetização é pensada de uma maneira mecânica, instrumental e de serventia acessória, sendo considerada só uma proposta para "grafar o aprendido na escrita" e, ainda, só no espaço escolar. No entanto, a própria autora chega a uma conclusão sobre a abrangência do significado do termo, anunciando que:

Então parece que, mesmo dividido entre a ilusão do controle e a deriva do sentido imposta pelo inconsciente e pela ideologia, o sujeito letrado e alfabetizado é, de fato, mais poderoso do que o sujeito letrado não-alfabetizado (TFOUNI, 1995, p. 97).

Este último detalhe enfatiza o que Braggio propõe nos seus estudos vistos acima, na condição de ideologia e dominação a partir do acúmulo do processo de alfabetização na criança. É possível observar que no seu livro Leitura e alfabetização (1992), Braggio critica o sistema de aquisição da linguagem no viés em que autores e cientistas a estudam como uma situação abstrata e ideal, que só serve para certas finalidades/instrumentalidades (p. 83).

É, nesse sentido, que o real da linguagem se apresenta, nos estudos de Braggio, como a ferramenta de observação do concreto, 
Imigração, língua de acolhimento e assimilação em Goiás Juan Alberto Castro Chacon

sob um suporte teórico de Bakhtin, Vygotzky, Luria e Freire com que a função da linguagem se torna real.

\begin{abstract}
A linguagem, porque produto da interação entre os homens, atualiza-se na enunciação dialógica, completa, num contexto de produção concreto, heterogêneo, multifacetado e contraditório, sendo sua natureza, portanto, intrinsecamente sócio-histórica e ideológica. Por não se tratar de um produto acabado, mas em permanente construção, num processo evolutivo ininterrupto qualitativamente caracterizado, não pode ser reduzida a uma norma Imutável, e nem a fala possuir caráter desviante (BRAGGIO, 1992, p. 83-84).
\end{abstract}

Por essa linha de raciocínio, acreditamos que o processo de alfabetização é uma sequência viva de realidades aprendidas ${ }^{1}$, ainda, quando o processo não é o aprendizado de crianças, e sim, de imigrantes das mais variadas faixas etárias. Entendemos que, por essa razão, Braggio (1992), nas suas leituras bakhtinianas, faz questão de propor a enunciação dialógica da linguagem como "heterogênea, multifacetada, contraditória, sócio-histórica e ideológica" e, por esses motivos, realizada a partir de uma leitura. E qual seria ela?

O professor Paulo Freire (1980) reflete sobre a leitura do mundo e o ato comunicativo de uma forma em que os dois são indissociáveis, ademais de se realizarem em concomitância que, no entanto, pode variar de ponto de vista. Isto é, a leitura está nas percepções e o ato comunicativo nas manifestações delas, em paralelo das suas partes, mas nem por isso como causa e efeito e nem inteiramente compreendida.

\footnotetext{
1 Por pesquisa anterior a este artigo, o autor do mesmo abre a discussão sobre alfabetização e letramento, num ponto em que ambos os conceitos passam a ser ações, mais ainda quando o termo letramento, segundo as pesquisas de Chacón (2021), encontra-se muito mais na ação para além da institucionalidade escolar.
} 
Imigração, língua de acolhimento e assimilação em Goiás

Juan Alberto Castro Chacon

Em torno de um fato - a colheita, por exemplo -, poderemos usar um sistema simbólico ininteligível para eles (os camponeses). Nossa linguagem técnica, que se exprime num universo de signos linguísticos próprios, pode deixar de ser alcançada por eles como o significante do significado sobre o qual falamos. Daí que as palestras sejam cada vez menos indicadas como método eficiente. Daí que o diálogo problematizador, entre as várias razões que o fazem indispensável, tenha esta mais: a de diminuir a distância entre a expressão significativa do técnico e a percepção pelos camponeses em torno do significado. Deste modo, o significado passa a ter a mesma significação para ambos. E isto só se dá na comunicação e intercomunicação dos sujeitos pensantes a propósito do pensado, e nunca através da extensão do pensado de um sujeito até outro (p. 68).

Nesta realidade, a política de alfabetização para o imigrante, como veremos, não é necessariamente uma imposição oficial, senão uma atitude de sobrevivência, dada a situação de margem em que ele se encontra. Justamente, alfabetizar-se numa cultura é lê-la, fazer o uso da leitura do seu redor (o novo redor no caso do imigrante) e compreender que há uma rede que interliga tudo aquilo que vê e sente.

Nesse sentido, é necessário expor sobre o que significa língua de acolhimento, para observar como eles leram e acolheram a língua portuguesa dentro das suas expectativas de projeção de vida presente/futura.

Embora não haja um conceito específico sobre o que é uma língua de acolhimento - seja pela complexidade que traz consigo o movimento humano com o termo acolher ${ }^{2}$, seja porque os movimentos migratórios, na sua grande maioria, implicam políticas atravessadas por problemas interseccionais (xenofobia, racismo etc) - pode-se dizer que ela se faz da necessidade de inserir o ser humano imigrante numa nova realidade linguística e sociocultural.

2 Para o dicionário Houaiss (2001), o termo acolher significa "dar ou obter refúgio, proteção ou conforto físico; hospedar(-se), abrigar(-se); reagir, receber, aceitar, atender a". Já para o dicionário Aurélio (2000) significa "dar agasalho ou acolhida a; atender, receber; tomar em consideração; dar crédito a; agasalhar-se, hospedar-se". 
No entanto, como supracitado, tudo depende de qual seja a projeção de vida do estrangeiro, inclusive, e como também já foi dito, porque as políticas públicas de migração da nação acolhedora formularam/formulam suas próprias pretensões "de acolhimento", como mencionamos adiante.

Essa reflexão se encontra, também, nos estudos de Amado (2013) sobre as políticas linguísticas para imigrantes no Brasil, quando menciona que "Embora o Brasil seja um país de imigrantes, está aquém de ter uma política de ensino do português como língua de acolhimento aos imigrantes" (p. 7). Nesse sentido, a língua portuguesa, como língua de acolhimento, será um alicerce cultural para a integração do imigrante, só se unida a uma política pública eficiente para a distribuição de tal código linguístico, como menciona Amado.

Além do mais, Amado (2013) aponta que devemos considerar que existe uma variedade de fontes linguísticas entre os imigrantes, como bagagem enriquecedora e como proposta que facilitaria o aprendizado da língua portuguesa:

O perfil de muitos dos imigrantes refugiados retrata falantes bilíngues e até multilíngues. Aqueles que vêm de países do continente africano falam, via de regra, além do inglês ou do francês, línguas étnicas e/ou línguas crioulas. O mesmo ocorre com boa parte dos falantes do continente asiático, como os sírios e palestinos, que, além do árabe, falam inglês. Ou dos haitianos que, a par do francês, falam o crioulo haitiano (p. 8).

Consequentemente, podemos afirmar que, muito mais do que um parâmetro linguístico de autorreconhecimento inicial numa cultura, a língua de acolhimento é um suporte paralelo ao da inserção sociocultural. E, neste contexto, também podemos colocar o desenvolvimento econômico do imigrante porque quem migra o faz por alguma razão de subsistência. Assim, quando Amado (2013) menciona sobre as bagagens bilíngues e multilíngues dos imigrantes mostra que a língua de acolhimento é uma necessida- 
Imigração, língua de acolhimento e assimilação em Goiás

Juan Alberto Castro Chacon

de a priori que, no entanto, pode se assimilar de uma forma afetiva ou criar outros contextos como a comparação, o etnocentrismo linguístico ou levar para um desarraigamento da língua de origem, entre outros fenômenos sociais. Tal como se apresenta a aquisição de línguas engloba um complexo sistema sociolinguístico, explicado por Braggio (1992), e como detalhamos adiante.

\section{Imigrações em Goiás}

Em primeiro lugar, devemos esclarecer que a imigração em Goiás só passa a ser contada (documentada) a partir da abolição da escravidão em diante (PALACÍN, MORAES, 2008, p. 103) ou, em todo caso, já entrado o séc. XX, posto que não se contabilizam os africanos, que vieram ao estado como mão-de-obra escravizada, como imigrantes. Tampouco, não há registro ou censo exato do número de portugueses ou a presença de outros estrangeiros no lugar, a não ser por comentários não registrados ou não arquivados devidamente. De fato, as empreitadas desbravadoras ou Bandeiras não são tomadas como migrações - bem como as descidas dos jesuítas do Pará - porque tinham outro propósito distinto ao que conhecemos como imigração ou colônia (p. 19).

É, nesse viés, que fazemos uma primeira discussão sobre imigração/imigrante e os contextos que os envolvem ou que envolva o processo de sair de um país, território ou espaço cultural, para trasladar-se a outro, com os fenômenos antropológicos que possam participar.

Seguindo esse raciocínio, é mister esclarecer o fator imigração como movimento humano em que se (des)encontram, no início, várias determinantes que se apoiam desde pontos de vista particulares, mas seguindo um olhar sociocultural. Estas características alimentam esperanças (projeções econômicas), comparações (etnocentrismo) e, sobretudo, o que resulta da troca das relações culturais (afetividade), em maior ou menor grau. 
Logo, toda imigração é um choque cultural, não necessariamente, no sentido bélico da palavra, senão da ideologia em que se colocam tanto o receptor/anfitrião/nativo quanto o acolhido/ migrante/estrangeiro. Assim, o que podemos caracterizar como cultura? Para Eagleton (2003), cultura é uma forma complexa para definir um conglomerado de representações, de uma identidade e de uma ideologia, com nova importância política (p. 184). Agregando, Santos (2009) menciona que "a discussão sobre cultura pode conduzir a falsas polarizações, como no caso da oposição entre erudito [e] popular, ou uma ideia de onipotência dos interesses dominantes [...]" (p. 83).

Já o professor Roque Laraia (2008), partindo de uma perspectiva antropológica, discute a ideia de que a cultura condiciona a visão do mundo do homem, cuja resposta será quase de imediata para se posicionar do centro para fora, no sentido daquilo que não condiz com a regra comunitária de um conglomerado cultural ( $p$. 67).

Por conseguinte, observamos que essas reflexões nos levam para a questão da identidade, do etnocentrismo e da diferença, no fato da cultura tomar corpo de instituição, mesmo não sendo formal ou oficial. Nesse sentido, a imigração estaria supervisionada informalmente pelo núcleo cultural, tanto do que foi deixado, quanto daquele que o recebeu. Isto é possível de se constatar no dizer de um parente ou amigo que emigrou para determinado país expressões como: "como tem mudado!" ou "virou inglesa/argentino etc", em relação aos hábitos e condutas adotadas no seu novo contexto sociocultural. Ou no sentido contrário, quando o anfitrião cultural expressa um "se acha um de nós!" ou "não tem sotaque!".

Assim, a identidade, como representação do indivíduo, está ligada à diferença, conquanto reconhecidas e atribuídas a um sistema de poder (SILVA, 2007, p. 91). Isto é, a relação da representação que se junta na identidade e na diferença é indissociável e dependente dela, permitindo que a cultura classifique a representação como parte da designação do poder cultural. Nesse caso, o etnocentrismo derivaria desse movimento já que é uma força que 
Imigração, língua de acolhimento e assimilação em Goiás

Juan Alberto Castro Chacon

colide com a representação do outro, Rocha (2006, p. 90), sobre os estudos antropológicos da cultura, menciona que:

Quaisquer que sejam as possibilidades da antropologia ela, ao menos, livrou-se, definitivamente, de confundir a singularidade cultural da sociedade do "eu" com todas as formas possíveis da existência do "outro". Quando pensamos na fuga ao etnocentrismo, que significa o questionamento de noções como "economia de subsistência" ou "tempo como história", vemos o quanto a antropologia já percorreu do caminho no sentido do "outro".

Ainda que as palavras de Rocha sejam positivas, em relação às formas teóricas de romper o choque cultural, acreditamos que na praxe esta colisão continua sendo inexorável, dada a institucionalidade - quase atávica - dos grupos culturais. Aliás, na cultura como instituição podemos ir um pouco além, se pensarmos que, no Brasil, entre o final do séc. XIX e o início do séc. XX, que se estendem até quase a primeira metade secular, desenvolveram-se políticas para uma "imigração ideal", no sentido poético, xenofóbico e racial da palavra. Um dos abolicionistas brasileiros mais conhecidos no mundo, Joaquim Nabuco (2002), escrevia sobre a importância de abolir a escravidão e trazer sangue caucásico, enérgico e sadio para o Brasil, e não chineses que poderiam corromper, mormente, a raça brasileira (p. 154).

Além disso, nos Governos de Getúlio Vargas, o extinto Ministério de Justiça e Negócios Interiores-MJNI elaborou uma série de leis nas quais se escolhia o ingresso ao Brasil, sobretudo para residência, dependendo do porte físico, mental e moral do imigrante, classificados em lista extensa (KOIFMAN, 2012, p. 301). Ainda, pode-se perceber o critério racial e segregacionista ou seletivo nesta política quando Koifman menciona que "na rigorosa observação do cumprimento das exigências enumeradas na lei era evidentemente mais rígida nos casos em que o solicitante era judeu ou "não branco". Seja nos pedidos permanentes ou temporários" ( $p$. 312). 
Imigração, língua de acolhimento e assimilação em Goiás

Juan Alberto Castro Chacon

Dessa forma, podemos ver que a imigração é um movimento muito complexo e que seria negligente conceituá-la de forma enciclopédica ou superficialmente positiva ou acolhedora, no sentido explicado pelos dicionários sobre o termo acolher. Assim, começaremos a descrição das culturas migratórias de fora do Brasil para Goiás, os grupos árabes, japoneses, italianos e sul-americanos. Aqui, tentamos observar e refletir sobre os diversos percursos que os ditos imigrantes realizaram para a sua permanência no Centro-Oeste brasileiro, assim como a sua assimilação à língua/cultura da região.

\section{a. Os povos árabes}

Na realidade, os povos árabes em Goiás não podem sofrer a metonímia cultural do todo pela parte, porque ao estado vieram sírios, libaneses, turcos e em menor número palestinos e egípcios, sendo estes últimos entre o continente africano e o Oriente Médio. Sendo assim, turcos, libaneses e sírios tiveram maior participação na formação do mundo cultural contemporâneo de Goiás e da capital, Goiânia, com grande relevância para suas particularidades pictóricas.

É possível afirmar que alguns indivíduos das etnias mencionadas já tinham percorrido as terras de Goyaz, quando ainda era província, em meados do séc. XIX, em ocupações comerciais como mascates (NUNES, 2000, p. 146) e regatões, sendo os últimos a versão fluvial dos mascates. Não obstante, ao não haver uma fonte sólida que comprove a veracidade sobre os nomes que fizeram história nesse tipo de transações comerciais, não realizamos mais comentários.

Portanto, a vocação comercial dos povos árabes em Goiás talvez seja o que mais se sobressai neles, caracterizando-os, posto que essas etnias tiveram maior representatividade no progresso de cidades como Catalão, Anápolis e Goiânia. Hoje em dia, é possível visualizar na Rua 4, no centro de Goiânia, lojas que mantêm o 
dono original: de origem turca, síria ou libanesa, embora tenha havido uma interferência do gentílico turco, que se estendeu para os da Síria e do Líbano pela influência do Império Otomano. O mesmo ocorre em Anápolis com várias lojas de tecido no centro da cidade, cujas características de venda são peculiares, em relação à publicidade e à ordem dos lugares. O urbanismo também se faz presente na representatividade da etnia de ascendência libanesa em Goiânia, já que a cidade possui uma avenida grande chamada República do Líbano, em homenagem aos precursores que atuaram na fundação e desenvolvimento da cidade goianiense.

Todavia, a integração não foi um percurso regular, como dito dos movimentos migratórios, porque:

Os imigrantes árabes não só alegavam as diferenças culturais como empecilhos aos casamentos interétnicos, mas também se apoiavam em determinados estereótipos em relação à mulher brasileira, alegando que elas eram insolentes e gastadeiras (NUNES, 2000, p. 136).

No sentido contrário, e linguisticamente falando, o homem dos povos árabes era designado como turco, sobretudo no sentido de comerciante desonesto, analfabeto, déspota e sujo, mas "nada ficou comprovado em relação ao analfabetismo dos imigrantes árabes pioneiros nem a outros aspectos ligados a doenças e à higiene" (Idem, p. 149).

Também, no sentido linguístico, com a suspensão de publicações em idiomas estrangeiros, em 1941, houve uma demanda forçada para o aprendizado da língua portuguesa no Brasil, com a qual se iniciou a tradução de jornais de outras etnias (p. 162). Talvez esse acontecimento tenha sido, para os imigrantes árabes, a aproximação sociolinguística da língua portuguesa mais decisiva, dentro da sua assimilação, porque aparte de "os árabes-goianos não se interessavam pela literatura árabe como seu (sic) pais" (p. 163), os mais velhos dedicaram seus investimentos na educação dos mais jovens. Motivo pelo qual se pode dizer que, embora exis- 
Imigração, língua de acolhimento e assimilação em Goiás

Juan Alberto Castro Chacon

tam topônimos de avenidas, nomes de estabelecimentos e alguns comércios que ressaltem a origem desses povos árabes, eles não seguiram uma linha de institucionalizar a sua língua e sua cultura, como os outros imigrantes que veremos adiante. Os imigrantes árabes tiveram uma grande assimilação sociolinguística, motivo pelo qual conseguiram continuar a sua trajetória de integração, passando do comércio ao mundo das profissões liberais, exercidas no estado, e até com participação no mundo da política.

\section{b. Os japoneses}

Diferentemente dos povos árabes que imigraram para o Brasil - Goiás, os povos japoneses vieram com ideias mais bem estabelecidas sobre "o que fazer?" nas terras americanas. Também chegaram um pouco mais tardiamente, sendo a procedência nipônica formada por uma multicultura agrícola e de trabalho artesanal.

Porém, o primeiro registro foi o anúncio de um veterinário japonês que residia na cidade goiana de Catalão direcionado aos imigrantes japoneses que se encontravam em São Paulo, falando sobre as oportunidades de obtenção de terras por um valor simbólico (MOTA, 2008, p. 26). Sobre esse quesito, cabe fazer uma adenda, à nota de curiosidade: a cultura japonesa seria um grupo étnico que dá valor agregado à palavra de um dos seus, como advertem algumas ficções romantizadas sobre ela, ou é algo culturalmente real? (p. 35).

Os imigrantes japoneses vieram se instalar logo nos municípios de Anápolis, Nerópolis, Goianápolis, Inhumas e Goiânia, em sua grande maioria e, com isso, organizaram-se em algumas representatividades para não perderem seus valores tradicionais ou para andarem juntos na empreitada. Como consequência desse movimento cultural nasce a Associação Nipo-Brasileira de Goiás em Goiânia (p. 28). Porém algumas outras iniciativas de organização acabaram se frustrando, como a Colônia Japonesa do Cerrado (p. 42). 
Imigração, língua de acolhimento e assimilação em Goiás

Juan Alberto Castro Chacon

Nesse caso, existe uma diferença marcante em relação aos imigrantes árabes em Goiás, visto que, por mais que estes últimos tenham tido um papel importante na urbanização e no movimento sociocultural em Goiás, não houve uma institucionalização de referência que ressaltasse as culturas árabes, como fizeram os japoneses. Por outro lado, o que sim resulta indiscutível é que ambas as etnias se tornaram imigrantes pela busca ou necessidade de prosperidade, perante as adversidades econômicas das suas terras natais (MOTA, 2008, p. 42).

Outro aspecto importante a destacar é o giro econômico dos japoneses em Goiás, a maioria deles dedicados aos trabalhos agrícolas, como supracitado, e por essa mesma razão em situações agravantes de estelionato e atropelo nas compras de terras. Isto, sobretudo, pela falta de entendimento linguístico quando começaram a se estabelecer, como menciona Mota (2008):

Como os imigrantes pretendiam retornar ao Japão, não havia interesse no domínio do português. De um modo geral, a assimilação da língua acontece, mais efetivamente, na terceira geração, pois a segunda ainda permanece em contato íntimo com a primeira (p. 42).

Essa reflexão é corroborada pelo depoimento da Sra. Maria Togo, filha de imigrantes japoneses, cujas palavras dizem que a mãe a levava consigo porque sabia falar melhor o português ( $p$. 52). Pelo contrário, o Sr. Jorge Sano disse que, como seus pais não souberam falar direito ${ }^{3}$, foram tapeados (p. 53). No entanto, é preciso mencionar que a cultura vinda da imigração japonesa em Goiás ainda prevalece como um legado sociolinguístico, num contexto de assimilação menor que a dos povos árabes. Isto é patente se vermos, por exemplo, a Escola Modelo de Língua Japonesa em Goiás, além da já citada Associação Nippo-brasileira em Goiás, e o

3 No caso, entendemos que "falar direito" se refere a que não sabia pronunciar o português, ao ponto de ser incompreendido, e não necessariamente a uma pronunciação correta da língua portuguesa. 
Imigração, língua de acolhimento e assimilação em Goiás

Juan Alberto Castro Chacon

Bon Odori, festa anual que se realiza no complexo cultural Kaikan, em Goiânia (p. 101).

Nesse sentido, podemos afirmar que a língua de acolhimento, no sentido de acolher, dos dicionários, não funciona no sentido de abrigar, mas sim como disposição in loco e temporal, com todas as complexidades étnicas e mesmo havendo uma tentativa de decodificá-la para uma necessidade semelhante. No caso dos povos árabes, com a língua portuguesa em Goiás, sentiram o acolhimento até um ponto elevado de assimilação linguística e cultural, quase um monolinguismo, inclusive na participação nos topônimos de diversos pontos da cidade goianiense. No caso dos japoneses, com a forma abrupta do primeiro momento linguístico, foram se adaptando ao Brasil e à cultura goiana (MOTA, 2008, p. 178), adquirindo o nível adequado para a compreensão da língua portuguesa, todavia, sem deixar o seu contexto sociolinguístico de origem.

\section{c. Os italianos}

A vinda dos italianos a Goiás está marcada por uma trajetória telúrica quase fixa: o município de Nova Veneza, antes pertencente ao município Anápolis ou Santana das Antas, mas quando ainda era um conglomerado de fazendas nas quais se podia ver a convivência de vários grupos étnicos.

A povoação que foi se estabelecendo na região cresceu como um núcleo em que conviviam, opondo-se e integrando-se, até formar uma nova sociedade... goianos, mineiros, italianos: entre vários segmentos apareciam as diferenças de quem era filho do lugar... havia as diferenças entre os que vinham de regiões brasileiras e os que vinham do exterior: percepções diferentes, frutos de vivências variadas, de sentimentos e de saudosismos nascidos em contextos específicos. Eram experiências diferentes que conviviam e concepções variadas em relação ao trabaIho e à vida, culturas diferentes que se aproximavam criando harmonias e choques... (STIVAL, 2011, p. 110). 
Imigração, língua de acolhimento e assimilação em Goiás

Juan Alberto Castro Chacon

Pode-se dizer que duas famílias foram as pioneiras para a empreitada migratória italiana, na antiga Província de Goyaz, durante o trajeto da "Marcha para o Oeste" brasileiro, cuja função era a colonização de terras e, não necessariamente, uma aventura, como o foi para os árabes, e as promessas de enriquecimento pronto com que foram atraídos os japoneses.

Os italianos tiveram outro princípio político dentro do Brasil, talvez como imigrantes ideais ${ }^{4}$ para a lavoura, o que facilitou seu ingresso e assimilação à agricultura e áreas afins, no que se refere ao café e outros plantios. Na sua trajetória para o oeste brasileiro, a etnia italiana soube aproveitar os espaços desde São Paulo, em grupos que se instalaram no seu interior. Minas Gerais também foi outro destino importante e os fluxos italianos também fizeram lá suas colônias para a lavoura e uma pecuária ainda tímida. Em Goiás não houve muita dispersão dos imigrantes italianos que para cá vieram, chegando e logo se estabelecendo no atual município de Nova Veneza, em que figuram como fundadoras as famílias Stival e Fachin (STIVAL, 2011, p. 111).

Os imigrantes ítalos se adaptaram à terra, aos costumes próprios de fazendas, à religiosidade, no entanto, houve certa complexidade na assimilação sociolinguística, embora, de alguma maneira, fossem mais entendíveis do que os povos árabes e os japoneses. A etnia italiana via que em Goiás a vida era muito mais fácil do que na Itália (p. 115), posto que os agricultores nativos do Brasil ainda tinham conhecimentos incipientes para tal exercício, sendo os europeus possuidores de experiência maior na área.

A questão da imigração italiana em Goiás - e fato controverso ainda - é a sua assimilação sociolinguística, porém tendo a língua de origem como marca identitária, o que os equipara, nesse quesito, aos japoneses. Se no momento da sua vinda para Goiás, como "uma forma de manter a unidade e a identificação era o uso da língua italiana, ou melhor do dialeto vêneto" (p. 117), hoje ainda existem políticas públicas de alfabetização que levam em conta a

4 Para o governo de Getúlio Vargas, os imigrantes ideais foram os lusitanos e os suecos, sem houver alguma explicação clara do porquê da escolha dos segundos, o que desata a polêmica da eugenia, na preferência por imigrantes de origem nórdica (KOIFMAN, 2012, p. 378). 
Imigração, língua de acolhimento e assimilação em Goiás

Juan Alberto Castro Chacon

língua italiana ${ }^{5}$. Vemos que, na atualidade, a língua italiana continua a funcionar como forma de unidade e identidade, embora a língua portuguesa seja majoritariamente falada. Aliás, o italiano no município de Nova Veneza tende a ser falado muito mais por pessoas anciãs e por crianças, as primeiras por uma questão de saudosismo e as últimas como parte de seu programa curricular em artes e lazer.

Nesse caso, o italiano funciona como um sistema linguístico de identidade para os descendentes dos imigrantes pioneiros, pois já não existe nenhum italiano vivo no município, pelo menos nenhum daqueles que chegaram. Assim, é possível observar que enquanto japoneses vivem a sua cultura como marca de costumes e folclores como maneira de vivificar as raízes, os italianos demonstram constantemente a sua aderência à cultura brasileira, mas ressaltando a permanência da sua língua de origem.

\section{d. Os sul-americanos}

A imigração de etnias sul-americanas para Goiás é bem mais recente do que os grupos citados anteriormente, sendo uma quantidade não tão grande, porém importante, a respeito do desenvolvimento do estado goiano. Embora não haja uma publicação bibliográfica detalhada sobre a migração sul-americana em Goiás, como a da dos povos árabes, japoneses e italianos, sabe-se, por meio de artigos jornalísticos sobre essas ondas migratórias. Assim, um artigo publicado no Diário de Goiás, de setembro de 20146, destaca que argentinos, paraguaios, chilenos, bolivianos e peruanos residem no estado como um núcleo migratório expressivo. Noutro jornal virtual, o Jornal UFG, discute-se a questão de migração como uma tendência a diminuir aqui no estado, em vista particularmente pela queda econômica brasileira, já que não é

5 Existe toda uma estrutura pública que favorece o ensino e a distribuição da língua italiana nas escolas públicas e em eventos oficiais culturais. Disponível em: https://novaveneza.go.gov.br/a-prefeita-patricia-fernandes-junto-com-o-seu-esposo-luiz-stival-realizam-a-estreia-do-filme-de-curta-metragem/. Acesso em: 25 fev. 2021.

6 Disponível em: https://diariodegoias.com.br/mais-de-8-mil-estrangeiros-vivem-em-goias-a-maioria-portugueses-norte-americanos-e-espanhois/. Acesso em: 25 fev. 2021. 
Imigração, língua de acolhimento e assimilação em Goiás

Juan Alberto Castro Chacon

mais um país tão atrativo quanto nas décadas anteriores ${ }^{7}$. O mesmo jornal aponta para novas etnias provenientes da África, Haiti e/ou do Hemisfério Sul e destaca que o fluxo migratório, em 2008, consistia em argentinos, bolivianos, uruguaios e paraguaios.

No entanto, podemos dizer que a etnia chilena é um dos grupos migratórios que conseguiu maior relevância na história de Goiás e na formação cultural da capital, Goiânia, como podemos ver nos comentários da página do Consulado de Relações Exteriores do Chile. Por motivo da fundação de uma organização cultural, o Consulado emitiu uma nota dizendo que os integrantes da organização cultural chilena em Goiás são aproximadamente "duzentos chilenos, plenamente integrados à sociedade civil goiana e formando famílias chileno-brasileiras"'. Esse depoimento corresponderia a uma assimilação sociolinguística com estimativas de aculturação - tema cuja explicação não será detalhada nesta pesquisa - com ênfase nas bases de proximidade territorial compartilhadas entre o Brasil e os demais países sul-americanos.

Existe a possibilidade de que os "duzentos chilenos" sejam mais do que essa cifra devido ao trânsito irregular do movimento migratório, além da probabilidade de alguns imigrantes não terem tido sucesso na petição oficial que os regulamentaria como residentes. Essa probabilidade se poderia aplicar, também, às outras etnias sul-americanas, mas enfatizamos a chilena porque tem desenvolvido relevantes trabalhos na cultura da sociedade goianiense, ao contrário de seus pares sul-americanos.

Não obstante, tudo indica que a assimilação linguística não acontece no ritmo em que o povo do acolhimento recepciona tais etnias migratórias, e talvez esse sentido irregular seja a característica mais importante da língua/cultura. No caso, o povo de acolhimento estaria alheio na disposição da sua própria língua, no que tange à assimilação das etnias imigrantes, funcionando esta (a língua) com certa receptividade para algumas e com receio, para ou-

\footnotetext{
7 Disponível em: https://jornal.ufg.br/n/107478-trabalhadores-imigrantes-em-goias-aumentam-319-em-8-anos. Acesso em: 25 fev. 2021.

8 Disponível em: https://chile.gob.cl/chile/blog/brasil/brasilia/surge-una-agrupacion-cultural-chilena-en-goiania-go. Acesso em: 25 fev. 2021.
} 
Imigração, língua de acolhimento e assimilação em Goiás Juan Alberto Castro Chacon

tras. É possível que este movimento de empatia linguística tenha a ver com semelhanças sociolinguísticas dos povos sul-americanos, no caso da língua espanhola, embora isto não seja um determinante linguístico ${ }^{9}$. E, de alguma maneira, o povo goiano também assimilaria e acolheria algumas condutas socioculturais dos seus imigrantes do mesmo continente, mais precisamente na cultura da alimentação. A distribuição de produtos chilenos como o vinho, de produtos argentinos como o doce de leite ou a demanda da culinária peruana como o ceviche, evidenciaria alguns pontos da imigração que se encontram invisíveis nos estudos em dados etnográficos ${ }^{10}$. Nessa perspectiva, esperamos que futuras pesquisas abordem a temática sul-americana, no sentido de aproximar esses intercâmbios culturais que se fixam, que parecem não existir a olho nu.

Por esse motivo, consideramos que a assimilação sociolinguística dos imigrantes sul-americanos é, propriamente, a mais próxima que as outras citadas, por questões geográficas, geopolíticas, históricas e, de alguma forma, econômicas. A língua portuguesa parece que não foi um empecilho, embora não seja muito parecida com a língua mais falada na América do Sul.

\section{O estado de Goiás e as migrações: perspectivas (in) comuns}

Para finalizar, tentamos esclarecer algumas problemáticas e contradições sobre a abordagem da língua de acolhimento, no seu contexto sociolinguístico, perante os grupos de imigrantes estudados que vieram residir no estado de Goiás. Com essa tarefa, não queremos fechar o olhar linguístico sobre imigração no estado, nem muito menos colocar verdades absolutas, visto que, como dizemos, a imigração representa um movimento, assim como a língua/cultura. Nesse aspecto, acreditamos que:

\footnotetext{
9 Disponível em: http://www.editorarealize.com.br/editora/anais/conbrale/2017/TRABALHO_EV080_MD1_SA8_ID412_10082017161209. pdf. Acesso em: 26 abr. 2021.

10 Não encontramos trabalhos que enfoquem o sentido da imigração no fator alimentar, nem virtual, nem bibliográfico.
} 
1. A colonização para residência na província de Goyaz, nos séc. XVII-XIX, não foi um movimento de imigração externa, e sim, o remanejamento das terras entre a população assentada nos maiores centros urbanos da época, como é o caso de São Paulo. E, também, como mencionamos, mesmo que tenha existido a possibilidade de haver imigrantes africanos nesse período, eles não possuíam ainda os direitos de cidadania. Logo, não há como catalogá-los como imigrantes, assim como tampouco se pode dizer sobre os movimentos exploratórios resultantes da extração de minérios (portugueses) ou da catequese (espanhóis). A província de Goyaz não era almejada como núcleo de urbanização, e sim, de exploração, na sua quase total maioria.

2. A aparição dos primeiros povoamentos em Goyaz do séc. XIX propunham os primeiros movimentos migratórios, porém também de gente de um Brasil em processo de miscigenação étnica, e não, de gente externa. É importante destacar dessa época a difusão da língua portuguesa e as vias de extinção das línguas originárias do lugar, enquanto políticas de colonização da Coroa portuguesa com os povoados autóctones da região goiana. Nesse caso, houve imigração linguística do português, de uma maneira impositiva e, em sentido contrário à assimilação deste ao novo panorama enfrentado, foram as línguas/culturas nativas as que assimilaram o novo padrão linguístico.

3. Para finais do séc. XIX, entrando ao séc. XX, é que se pode afirmar, com os registros referenciais descritos, que a imigração externa chega em Goyaz/Goiás e com ela os diferentes mundos sociolinguísticos do português. Assim, os choques culturais são inevitáveis, perante uma sociedade goiana com algumas bases socioculturais e ideológicas já formadas e os grupos étnicos recém-chegados, no caso árabes e italianos em primeiro lugar e, posteriormente, os japoneses. Vale mencionar que também houve outros grupos étnicos que não citamos nesta pesquisa, em razão da falta de dados para maiores esclarecimentos sobre a nossa hipótese, como é o caso dos alemães e dos portugueses em Goiás. Nesse aspecto, os choques culturais funcionam como ferramentas 
de medição etnográfica no sentido de alimentarem comparações etnocêntricas, afetividades (saudosismos) e criação de identidades via assimilação. Geralmente, o choque cultural é determinado no primeiro encontro de aproximação.

4. Estabelecido o estado de Goiás, com sua nova capital Goiânia na década de trinta do séc. $\mathrm{XX}$, o desenvolvimento migratório passa a fazer parte de programas de censo, de pesquisa e de atuação política, como resultado das ações governamentais nas políticas de migração externa. Aqui observamos três níveis diferentes de assimilação sociolinguística, no que se refere ao português como língua de acolhimento. Primeiro, os povos árabes - praticamente os imigrantes externos pioneiros - desenvolveram-se no setor comercial como meio de subsistência, posto que, na sua grande maioria, tinham a experiência em mercado, e o adjetivo pejorativo turco assim parece ratificá-lo. Os árabes, ainda que bem arraigados à pátria que ficou atrás, conseguiram uma assimilação sociolinguística maior, o que poderia ser uma resposta à sua não prática institucional da sua língua/cultura (não há escolas exclusivas de línguas árabes em Goiás). Além disso, eles tiveram um grande papel na construção política e cultural de Goiânia, como fica patente nos monumentos e nos topônimos de avenidas, praças e parques da capital. No caso dos japoneses residentes em Goiás, nos diversos municípios e na capital, aconteceu uma assimilação sociolinguística de uma forma diferente da dos árabes. Um dos motivos para isto talvez esteja no espírito de empreendedor com que os primeiros imigrantes japoneses vivenciaram seus primeiros anos no estado, já que vieram com capital para adquirir terras, não necessariamente, como comerciantes, nem como mão-de-obra. O segundo motivo está no forte arraigo com o Japão, posto que a maioria queria fazer dinheiro e voltar, sendo desnecessário, no momento, aprender a língua portuguesa, por conseguinte, adentrar-se à cultura goiana. $O$ terceiro motivo deriva do anterior porque, para sobrevivência, tiveram que criar núcleos e associações culturais, no primeiro momento, mas que foram se fixando com o passar do tempo, permanecendo até hoje. 
Consequentemente, os imigrantes japoneses, sobretudo a segunda geração, tiveram de aceitar a língua/cultura do lugar, abrindo seus espaços mercantis para outros rumos, como profissionais liberais e diversas outras áreas que não especialmente a agricultura.

Em relação aos italianos, também percebemos que existe uma variante de assimilação sociolinguística que os difere dos árabes e dos japoneses, no caso porque a Itália sim fornecia ao mundo mão-de-obra, além da disposição na crescente demanda da época para o setor industrial. A variante de assimilação do português não só aponta o saudosismo da pátria como fator contrário ao aprendizado do novo idioma, mas à própria cultura do trabalho contínuo no país de origem. Este olhar etnocêntrico foi fortalecido, também, pelo quase isolamento da língua/cultura italiana em Goiás, estando os seus núcleos familiares quase todos no município de Nova Veneza. O revés do etnocentrismo da etnia italiana encontra-se nas políticas com que se manteve até hoje, em que português e italiano convivem em espaços oficiais, como supracitado, produto da colaboração dos descendentes dos imigrantes, durante o tempo em que ocuparam funções públicas. Nesse viés, a cidade vive um sistema sociolinguístico de via dupla, mas em concomitância, e propõe que, embora os moradores da cidade não falem o italiano com fluência, inclusive muitos nem o falam, eles ressaltam o valor cultural à língua do imigrante externo.

Por último, os imigrantes sul-americanos, dos quais não temos um aporte referencial bibliográfico, mas virtual e ainda escasso. Uma das suas características, o que é preciso dizer sobre eles, é a posterioridade com a que chegaram a Goiás, sobretudo na capital do estado, e que também se faz necessário um trabalho mais profundo sobre sua residência e suas observações culturais. Nas descrições que discutimos, obtivemos informações sobre os chilenos como grupo étnico de maior participação no desenvolvimento sociocultural, com cineclubes, círculos de debate etc., e aqui podemos agregar a participação do poeta Pablo Neruda nos 
Imigração, língua de acolhimento e assimilação em Goiás Juan Alberto Castro Chacon

dias de fundação de Goiânia como capital ${ }^{11}$. As outras etnias sul-americanas imigrantes são relativamente mais jovens e, a priori, podem passar como assimiladas linguisticamente na sua totalidade, pela falta de estudos sobre eles no contexto goiano ou goianiense.

No entanto, fazemos a colocação da troca sociocultural pelas realidades semelhantes, nas que alguns países sul-americanos, o Brasil incluído, são considerados países emergentes. Outro ponto de semelhança estaria na proximidade das línguas, pois historicamente o espanhol e o português são consideradas línguas primas-irmãs. Dessa forma, tentamos detalhar que a assimilação sociolinguística dos imigrantes sul-americanos se daria de maneira mais prática e/ou eficiente no tempo, porém nem por isso sem complexidades.

\section{Considerações Finais}

Perante as temáticas trabalhadas, esta pesquisa considera que, em primeiro lugar, língua e cultura são indissociáveis na medida em que representam movimentos próprios, reais, e que estão em constante perigo de manipulação ideológica. Assim, língua de acolhimento, destacando o termo acolher, propõe diferentes realidades de choque, seja por refúgio, seja por migração, e não é só uma perspectiva enciclopédica ou manual romantizada. No caso, no acolhimento prevalecem as relações socioculturais, ideológicas e afetivas do anfitrião e do imigrante, relações que criam tensões e expectativas.

Essas tensões e expectativas se dão de maneiras distintas, em situações diferentes, dadas as proximidades e as distâncias, talvez sociolinguísticas, talvez econômicas, ou em fatores que tenham que ver com a segregação racial, xenofobia, classismo, sexismo etc. Nessa interpretação, a assimilação sociolinguística é um produto em processo inacabado de construção social, porque não funcio-

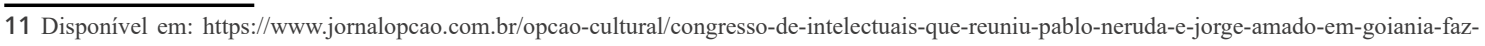
-65-anos-166579/. Acesso em: 27 abr. 2021. 
Imigração, língua de acolhimento e assimilação em Goiás

Juan Alberto Castro Chacon

na da mesma forma para todos os involucrados e porque pode despertar formas futuras de contradição, dissimilações, como na atualidade dos imigrantes venezuelanos em certas regiões sul-americanas, ou dos imigrantes haitianos no Brasil. Os venezuelanos, tendo uma crise governamental e desencontros internos, veem-se cada vez mais espalhados por toda América Latina e, no caso dos haitianos, pela situação crítica da economia brasileira, muitos decidiram abandonar o país para se adentrarem aos fronteiriços como Peru, por exemplo.

Por esse motivo, refletimos que identidade é uma variável que se apoia na sincronia do construto social real, ou seja, identidade não possui um sentido fixo, nem representa o ethos de um indivíduo pela pátria. Assim, identidade e assimilação linguística admitem, para sua formulação, coerências que vão além da proximidade geográfica, da semelhança política ou da ética humana. É, com essas características, com que funcionaria uma das formas de aquisição de uma língua, a do imigrante.

\section{Referências}

AMADO, Rosane de Sá. O ensino de português como língua de acolhimento para refugiados. Revista da SIPLE, Brasília, ano 4, n. 2, out 2013. ARNOLD, Jane. La dimensión afectiva en el aprendizaje de idiomas. Traducción Alejandro Valero. Madrid: Cambridge University Press, 2000. BRAGGIO, Silvia Lucia Bigonjal. Leitura e alfabetização: da concepção mecanicista à sociopsicolingüística. Porto Alegre: Artes Médicas, 1992. EAGLETON, Terry. A ideia de cultura. 2. ed. Tradução Sandra Castello Branco.São Paulo: Editora UNESP, 2011.

FACHIN, João; STIVAL, Eleildo; STIVAL, Paulino. Da Itália para o Brasil: a história dos fundadores, a fundação de Nova Veneza. Goiânia: Kelps, 2011.

FREIRE, Paulo. Extensão e comunicação? 4. edição. Rio de Janeiro: Paz e Terra, 1980. 
Imigração, língua de acolhimento e assimilação em Goiás Juan Alberto Castro Chacon

KOIFMAN, Fábio. Imigrante ideal: o Ministério da Justiça e a entrada de estrangeiros no Brasil (1941-1945). Rio de Janeiro: Civilização Brasileira, 2012.

LARAIA, Roque. Cultura: um conceito antropológico. 22. ed. Rio de Janeiro: Jorge Zahar Editor, 2008.

MOTA, Fátima Alcídia Costa. Meia volta ao mundo. Imigração japonesa em Goiás. Goiânia: Gráfica e Editora Bandeirante Ltda., 2008.

NABUCO, Joaquim. $\mathbf{O}$ abolicionismo. 2. ed. Rio de Janeiro: Editora Nova Aguilar, 2002.

NUNES, Heliane Prudente. A imigração árabe em Goiás. Goiânia: Editora da UFG, 2000.

PALACIN, Luis; MORAES, Maria. História de Goiás. 7. ed. Goiânia: Editora da UCG, Editora Vieira, 2008.

ROCHA, Everaldo P. Guimarães. O que é etnocentrismo. São Paulo: Brasiliense, 2006.

SANTOS, José. O que é cultura. São Paulo: Brasiliense, 2006.

SILVA, Tomaz Tadeu. Identidade e diferença: a perspectiva dos estudos culturais. 7. ed. Petrópolis: Vozes, 2007.

TFOUNI, Leda. Letramento e alfabetização. 8. ed. São Paulo: Cortez, 2006. 